\title{
Do contrato administrativo: modalidades e cláusulas exorbitantes
}

\author{
The administrative contract: modalities and exorbitant clauses
}

Victor Ribeiro Travain ${ }^{1}$

\begin{abstract}
Resumo
Busca-se com este estudo apresentar uma explanação clara a respeito dos contratos administrativos, bem como de suas modalidades e suas cláusulas exorbitantes. Procura-se proporcionar uma distinção sobre as diversas modalidades de contrato administrativo, apontando suas características essenciais. Na parte das cláusulas exorbitantes intenciona-se a demonstrar a importância da supremacia do interesse publico sobre o privado, o que faz distinguir esses contratos dos contratos civis.
\end{abstract}

Palavras Chave: Contratos Administrativos; M odalidades; Cláusulas Exorbitantes.

\begin{abstract}
This paper intends to present a clear explanation about the administrative contracts, as well as their modalities and their exorbitant clauses. Tries to demonstrate the differences between the many kinds of administrative contract, pointing out their essential features. In the exorbitant clauses intends to show the importance of the supremacy of public interest over private, most important difference from these contracts to the civil Law contracts.
\end{abstract}

Keywords: Administrative Contracts; Modalities; Exorbitant Clauses.

\section{Introdução}

O contrato, ordinariamente estudado no Direito Civil, consiste num acordo de vontade entre as partes contratantes que se comprometem a prestações recíprocas e estão desautorizadas a alterá-lo ou extingui-lo unilateralmente. No contrato do âmbito civil, ambos os signatários serão, na maioria das vezes, entes privados.

A Administração Pública, por sua vez, pode celebrar contratos com entes privados sob duas formas: Contratos da Administração Pública e Contratos Administrativos. Os

\footnotetext{
${ }^{1}$ Estudante do 50 ano de Direito na UEL.
} 
primeiros regidos pelo Direito Civil e os segundos pelo Direito Administrativo. Os regidos pelo Direito Civil visam sempre ao lucro (inclusive da Administração), enquanto que os demais objetivam à realização de um serviço público.

É justamente por essa objetivação diversa dos demais que os contratos administrativos possuem características peculiares, regidas principalmente pelo Princípio da Supremacia do Interesse Público Sobre o Privado e outros tantos norteadores da Administração Pública.

Essas peculiaridades são as chamadas cláusulas exorbitantes do contrato administrativo, e são assim denominadas pois conferem privilégios a uma das partes, a Administração Pública. Tais cláusulas, caso inseridas em um contrato normal do Direito Civil, feririam o princípio da paridade entre os contratantes e seriam consideradas ilegais ou, ao menos, inadequadas.

São inúmeras as cláusulas ditas exorbitantes e, ainda, pode-se salientar a existência de disposições legais ou mesmo orientações jurisprudenciais que geram divergências na doutrina sobre a sua classificação ou não como tal. Dentre as unânimes e mais consagradas, observa-se o equilíbrio econômico-financeiro, a fiscalização do contrato, a aplicação de penalidades contratuais, entre outras.

0 presente trabalho pretende abordar com mais afinco os temas ditos acima, como conceito de contrato administrativo, diferenças para o contrato civil, aplicabilidade e especificidades das principais cláusulas exorbitantes.

\section{Contrato administrativo}

Contrato, em seu sentido amplo, é um ato jurídico bilateral, sempre norteado por pelo menos duas manifestações de vontade e que tem como objetivo a criação, modificação ou extinção de direitos e deveres. Os contratos, portanto, são todos os acordos ou combinações oriundos da vontade das partes (TARTUCE, 2011, p. 472).

Quando realizada uma análise dos contratos celebrados pela Administração Pública, são constatadas duas formas distintas de contratar, a saber, os Contratos da Administração Pública e os Contratos Administrativos. Os primeiros possuem características de Direito Privado, ou seja, englobam-se no acordo de vontade do qual foi falado anteriormente, tendo por característica a paridade entre as partes e as prestações recíprocas entre os 
contratantes. Estes contratos são comumentes utilizados quando a Administração Pública celebra atos próprios de uma instituição privada, como compra, venda ou locação de bens (PIETRO, 2009, p. 254).

Já o Contrato Administrativo, por sua vez, possui características peculiares, pois é a partir dele que a Administração opera os serviços essenciais ao bem estar comum. Portanto, de acordo com o Princípio Constitucional da Supremacia do Interesse Público sobre o Privado, como esses contratos visam à celebração de atos à população em geral, são regidos pelas normas de Direito Público. Admite-se, porém, a aplicação das normas de Direito Privado, mas somente de forma complementar aos institutos de natureza pública (M ELLO, 2005, p. 576).

\section{Diferenças para o contrato civil}

As diferenças entre as modalidades contratuais supracitadas dizem respeito diretamente às prerrogativas atribuídas à Administração. Isso porque no que concerne às exigências de forma, procedimento, competência e finalidade ambos obedecem às mesmas normas.

Como dito anteriormente, o contrato no âmbito do Direito Civil é aquele celebrado entre as partes, através de pelo menos duas declarações de vontade e capaz de gerar direitos e obrigações para os contratantes (TARTUCE, 2011, p. 472).

A grande diferença que se pode apontar no contrato entre particulares para o contrato administrativo está no fato de naquele os contratantes, ou signatários, estarem em paridades de condições, ou seja, todos os direitos quanto a celebração, cumprimento, extinção, etc. deverão ser iguais - contratos sinalagmáticos (M ONTEIRO, 2003, p. 213).

Enquanto isso, o contrato administrativo, por força do já citado Princípio da Supremacia do Interesse Público, confere atribuições excepcionais à Administração Pública que no âmbito civil seriam consideradas completamente inadequadas ou ilegais².

\footnotetext{
${ }^{2}$ Por inadequadas, compreendem-se aquelas atribuições que, ainda que inusuais, podem existir nos contratos privados, desde que pactuadas livremente pelas partes e que não fira disposição expressa de lei. Por ilegal, entendem-se aquelas cláusulas que dão poderes tal a uma das partes que só seria permissível à Administração Pública, como aplicação de penalidades contratuais e retomada do objeto (PIETRO, 2009, p.257).
} 
Como exemplo dessas distinções, pode-se apontar que, enquanto no Direito Civil os contratos regem-se pelos princípios da força obrigatória do contrato, em virtude da chamada pacta sunt servanda (VENOSA, 2004, p. 390), nos contratos administrativos imperam regras como possibilidade de alteração e rescisão unilateral, retomada do objeto do contrato, restrições quanto à exceção de contrato não cumprido, sempre em favor do ente público (SPITZCOVSKY, 2008, p. 324).

Outra distinção cuja menção se faz importante é a que se refere à finalidade dos contratos. 0 administrativo tem como uma de suas características mais importantes a finalidade pública, ou seja, todo contrato celebrado nesta forma visa sempre à prestação do serviço inerente ao Estado, abrangendo a satisfação de toda a população. Ao contrário do contrato privado, o assinado pela Administração Pública não pode se pautar apenas nas vontades específicas de seus signatários, ou mesmo de apenas um grupo de pessoas, devendo seguir os anseios de toda a população (M EDAUAR, 2009, p. 219).

\section{Modalidades de contrato administrativos}

0 gênero contrato administrativo pode ser divido em várias espécies, também denominadas de modalidades desses contratos. Estas se apresentam em grande número na legislação pátria, sendo a principal delas o contrato de concessão, em virtude de sua maior utilização pela Administração Pública. Porém, há ainda outras modalidades de importante destaque, sendo, assim, tratadas individualmente na sequência.

\section{Concessão}

A concessão, modalidade mais utilizada pela Administração Pública, consiste na transferência de titularidade de poderes e deveres da Administração para outra pessoa, que assumirá a competência para a realização dos serviços.

A concessão é um contrato bilateral, regido pelo Direito Administrativo, oneroso e com prazo determinado (BRAZ, 2009, p. 599). Sua bilateralidade decorre do fato de a Administração celebrá-Io, necessariamente, com um sujeito alheio a ela. A regência do Direito Administrativo se dá em virtude da presença das cláusulas exorbitantes, que serão estudadas mais a frente e que só são aplicáveis nos contratos desse gênero. A onerosidade 
implica a contraprestação das duas partes, ou seja, a partir da celebração do contrato ambas as partes assumem direitos e deveres entre si (PIETRO, 2009, p.290).

Neste tipo de contrato, admitir-se-á a subconcessão, desde que esteja prevista expressamente no edital e, assim como todo negócio celebrado no âmbito administrativo, deverá ser precedido de concorrência. 0 subconcessionário sub-rogará todos os direitos e deveres antes do concessionário original, com exceção de ressalvas feitas na própria subconcessão (BRAZ, 2009, p. 602).

A partir do momento em que se celebra o contrato de concessão, todas as responsabilidades pela execução da prestação serão incumbidas ao concessionário. Independente de fiscalização imposta pelo órgão concedente, todo prejuízo que ele venha a sofrer em virtude do concessionário, será de responsabilidade deste, assim como a responsabilidade pela contratação de funcionários. Importante ressaltar, nesse aspecto, que as contratações (empregatícias ou não) celebradas pelo concessionário com terceiros, serão de responsabilidade exclusiva daquele, não se estendendo em nada à Administração Pública (BRAZ, 2009, p. 601-602).

Não obstante essas responsabilidades atribuídas ao concessionário, a Lei 8.987/95, em seu art. 29, apresenta alguns encargos à Administração nesse tipo de contrato. Segue:

Art. 29. Incumbe ao poder concedente:

I - regulamentar o serviço concedido e fiscalizar permanentemente a sua prestação;

II - aplicar as penalidades regulamentares e contratuais;

III - intervir na prestação do serviço, nos casos e condições previstos em lei;

IV - extinguir a concessão, nos casos previstos nesta lei e na forma prevista no contrato;

$\mathrm{V}$ - homologar reajustes e proceder à revisão das tarifas na forma desta Lei, das normas pertinentes e do contrato;

$\mathrm{VI}$ - cumprir e fazer cumprir as disposições regulamentares do serviço e as cláusulas contratuais da concessão;

VII - zelar pela boa qualidade do serviço, receber, apurar e solucionar queixas e reclamações dos usuários, que serão cientificados, em até trinta dias, das providências tomadas;

VIII - declarar de utilidade pública os bens necessários à execução do serviço ou obra pública, promovendo as desapropriações, diretamente ou mediante outorga de poderes à concessionária, caso em que será desta a responsabilidade pelas indenizações cabíveis;

IX - declarar de necessidade ou utilidade pública, para fins de instituição de servidão administrativa, os bens necessários à execução de serviço ou obra pública, promovendo-a diretamente ou mediante outorga de poderes à concessionária, caso em que será desta a responsabilidade pelas indenizações cabíveis;

ReVISTA de Direito Público, Londrina, V. V. 6, N. 3, P. 3-20, OUT/DEZ. 2011. 
$X$ - estimular 0 aumento da qualidade, produtividade, preservação do meio ambiente e conservação;

XI - incentivar a competitividade; e

XII - estimular a formação de associações de usuários para defesa de interesses relativos ao serviço.

A realização do exercício da fiscalização a que alude o artigo anterior será tratada adiante nos aspectos das cláusulas exorbitantes.

Por fim, ainda no campo das concessões, cumpre salientar a existência de várias espécies de concessão.

A concessão de serviço público, mais habitual, é aquela que o poder público transfere a terceiro a execução de serviço público, por meio de concorrência, por conta e risco do particular e mediante remuneração (M EDAUAR, 2009, p. 216).

Sobre essa concessão, ainda dispõe Maria Sylvia Zanella di Pietro:

Concessão de serviço público é o contrato administrativo pelo qual a Administração Pública delega a outrem a execução de um serviço público, para que execute em seu próprio nome, por sua conta e risco, assegurando-Ihe a remuneração mediante tarifa paga pelo usuário ou outra forma de remuneração decorrente da exploração do serviço (PIETRO, 2009, p.291).

Já a concessão de uso de bem público, por sua vez, é o ato "pelo qual a Administração consente que particular tenha uso privativo de bem público - exemplos: concessão de uso de área de mercado municipal[...]" (M EDAUAR, 2009, p. 217).

Por último, a concessão florestal ocorre quando a Administração concede autorização para que empresa privada, em consórcio ou não, exerça o direito de exploração sustentável de produtos e serviços numa unidade de manejo (M EDAUAR, 2009, p. 218).

\section{Gestão}

O contrato de gestão foi introduzido no ordenamento jurídico brasileiro sob 0 prisma constitucional a partir da Emenda Constitucional nํ. 19 de 1998, que introduziu o $\S$ 8 ao artigo 37 da Constituição Federal.

Este tipo de contrato visa a uma harmonia entre a Administração Pública Direta e Indireta, objetivando o estabelecimento de determinadas metas à Administração Indireta que, uma vez alcançadas, renderiam algum benefício outorgado pelo Poder Público (PIETRO, 2009, p. 333). 
Assim, a Administração Indireta acaba por tornar-se mais autônoma, não só pela imposição de metas, mas também pela fixação de meios de redução de custos, controle de produtividade, dando a Administração Direta subsídios para decidir sobre a manutenção ou não desse contrato. Em outras palavras, o contrato de gestão visa a adequar a prestação de serviços público através da descentralização ou desconcentração (AGUILAR, 2004).

Por fim, autores ainda salientam a equivocação em se utilizar o termo "contrato" nesses compromissos. Como estudado anteriormente, a celebração de um contrato válido exige a participação de pessoas capazes. Assim, quando a Administração Pública Direta contrata com a Indireta, essa capacidade desaparece. Ou seja, a Administração, quando contrata, sempre o faz em nome da pessoa jurídica a que está ligada; e nesse tipo de contrato a Administração figura em ambos os pólos do negócio. Contudo, considera-se impossível o mesmo ente capaz ter interesse em ambos os lados do contrato. Pelo exposto, sustentam diversos autores que o correto seria configurar tal negócio como convênio, o que não foi ainda realizado pelo legislador (AGUILAR, 2004).

Obras

A Lei 8.666/93 em seu artigo 60, I define como obra "toda construção, reforma, fabricação, recuperação ou ampliação, realizada por execução direta ou indireta". Partindose, portanto, dessa lei, pode-se definir que o contrato de obras é todo aquele realizado pela Administração Pública com ente particular (execução indireta) cujo objetivo é realizar qualquer das atividades discriminadas no inciso transcrito.

O contrato de obras pode ser feito sob quatro regimes, disciplinados no inciso VIII, do mesmo artigo. Acerca destes regimes, ensina Odete Medauar:

Se a obra é contratada para realização por particulares, trata-se de execução indireta, sob qualquer dos seguintes regimes: a) empreitada por preço global, quando contratada por preço certo e total; b) empreitada por preço unitário, quando é fixado preço por unidades determinadas (por exemplo, metro de área construída); c) tarefa, quando se ajusta mão-de-obra para pequenas obras, por preço certo, com ou sem fornecimento de materiais; d) empreitada integral, no caso em que o empreendimento é contratado de modo completo, sob inteira responsabilidade da contratada até a entrega ao contratante em condições de início de uso (art. 60, VIII) (MEDAUAR, 2009, p. 215-216).

Parcerias Público-privadas 
A chamada parceria público-privada é uma modalidade recente de contrato administrativo, instituída pela lei 11.079 de 2004. Segundo análise do próprio texto legal percebe-se a existência de duas modalidades de parcerias, a patrocinada e a administrativa (art. 2ㅇ) ).

Ao definir o conceito de parceira público-privada, Maria Sylvia Zanella de Pietro tece com clareza:

[...] pode-se dizer que a parceria público-privada é o contrato administrativo de concessão que tem por objetivo (a) a execução de serviço público, precedida ou não de obra pública, remunerada mediante tarifa paga pelo usuário e contraprestação pecuniária do parceiro público, ou (b) a prestação de serviço de que a Administração Pública seja a usuária direta ou indireta, com ou sem execução de obra e fornecimento e instalação de bens, mediante contraprestação do parceiro público. (PIETRO, 2009, p.306)

Ao cuidar do conceito de parceria público-privada, Pietro já distinguiu também as duas modalidades supracitadas, concessão patrocinada e administrativa.

A concessão patrocinada vem tratada no $§ 1^{0}$ do art. $2^{\circ}$ da referida lei. Assim, será concessão patrocinada todas aquelas concessões previstas no item 3.1 do presente artigo e que envolva uma contraprestação pecuniária do ente público, além da tarifa cobrada do usuário. Em muito se confunde a parceria público-privada na modalidade concessão patrocinada com a concessão de serviços públicos, entretanto, é justamente essa contraprestação por parte do Estado que os diferenciam. 0 próprio dispositivo legal, no art. 2,$\S 30$ cuida de tratar dessa diferença e ressalta que, em não havendo essa contraprestação pecuniária, não se configurará a parceria público-privada.

Já a concessão administrativa, como o próprio nome sugere, é a prestação de serviços de que a Administração Pública seja a usuária direta ou indireta (\$2º). Sobre o tema, segue Pietro:

Ao contrário da concessão patrocinada, que tem por objetivo a execução de serviço público, a concessão administrativa, à primeira vista, tem por objetivo a prestação de serviço (atividade material prestada à Administração e que não tem as características de serviço público). Vale dizer que haveria uma aproximação conceitual entre esse contrato e 0 contrato de serviços de que trata a Lei $n-$ 8.666/93, sob a forma de empreitada (arts. 60, VIII, e 10) (PIETRO, 2009, p.310).

Segue, mais adiante, elucidando seu pensamento: 
No entanto, não é possível identificar inteiramente a concessão administrativa com a empreitada. Em primeiro lugar, porque, na primeira, o parceiro privado sujeitarse-á às normas da Lei no 11.079, da Lei no 8.989 (arts. 21, 23, 25 e 27 a 39) e da Lei no 9.074/95, enquanto na segunda aplica-se a Lei no 8.666/93.

Em segundo lugar, apesar da impressão que decorre do conceito legal contido no artigo $2^{\circ} \circ, 2^{\circ}$, outros dispositivos permitem inferir que a concessão administrativa poderá ter por objeto a prestação de serviço público, até porque a lei expressamente veda a concessão patrocinada ou administrativa "que tenha por objetivo único o fornecimento de mão de obra, o fornecimento e instalação de equipamentos ou a execução de obra pública" (arts. 2ํ, §4으, inciso III) (PIETRO, 2009, p. 311)

Por fim, merece destaque que, apesar das diferenciações entre essas modalidades, existem normas gerais quanto à parceria público-privada e que se aplicam às duas modalidades, como contraprestação pecuniária paga pelo Estado; equilíbrio econômicofinanceiro; compartilhamento de ganhos econômicos, delimitação do prazo contratual; observância da Lei de Responsabilidade Fiscal; imposição de limites de despesas; e necessidade de licitação. (PIETRO, 2009, p.313-315)

Incidência das cláusulas exorbitantes

As chamadas cláusulas exorbitantes do contrato administrativo são aquelas inseridas nesta modalidade contratual justamente para garantir que as distinções entre esse contrato e o de Direito Privado sejam asseguradas.

São essas cláusulas as responsáveis por assegurar que a Administração Pública possua uma posição de superioridade em relação ao outro polo contratual, obedecendo assim o Princípio da Supremacia do Interessa Público.

A expressão exorbitante é utilizada em referência aos contratos privados, pois, caso neles fossem utilizadas, essas cláusulas seriam consideradas abusivas por determinar quebra da paridade de direitos e deveres (M EDAUAR, 2009, p. 219).

Grande parte dessas cláusulas, entre elas as mais importantes, é prevista no art. 58 e incisos da Lei no. 8.666 de 23 de junho de 1993, sob a denominação de prerrogativas da Administração. As principais serão tratadas na sequência.

\section{Exigência de Garantia}


Esta cláusula facultativa do contrato administrativo consiste no direito da Administração Pública exigir garantias a fim de assegurar a execução correta e tempestiva do contrato a ser celebrado. Serão admissíveis essas garantias nos contratos de obras, serviços e compras e, uma vez exigidas, caberá ao contrato escolher qual pretende prestar, dentre caução em dinheiro ou títulos da dívida pública, seguro-garantia ou fiança bancária (art. 56, $\S 1$, I, II e III da Lei 8.666/93).

Cumpre ressaltar que, apesar do caráter facultativo desta exigência, caso a autoridade competente opte por fazê-la, deverá tal imposição estar prevista desde logo no instrumento convocatório da licitação. Ademais, a referida lei permite que a Administração recolha essa garantia já a partir da licitação, "para efeito de garantia ao adimplemento do contrato a ser ulteriormente celebrado" (art. $31 \S 2^{\circ}$ ). Nesse caso, os licitantes perdedores reaverão as garantias prestadas assim que se encontrarem em tal situação (PIETRO, 2009, p. 268).

A garantia, ao ser exigida, permanece com a autoridade pública até a completa execução do contrato, momento em que deverá ser reavida pelo contratado. A Administração, porém, em caso de inadimplemento por parte do particular, poderá reter tais garantias como indenização pelos prejuízos sofridos e como recebimento das multas e indenizações a ela devidas (PIETRO, 2009, p.268).

Alteração e rescisão unilateral do contrato

A alteração unilateral do contrato está prevista no art. 65, I da Lei 8.666/93 que, além da permissão para sua realização, determina também as condições para que ela se realize. Assim estabelece 0 artigo:

Art. 65. Os contratos regidos por esta Lei poderão ser alterados, com as devidas justificativas, nos seguintes casos:

I - unilateralmente pela Administração:

a) quando houver modificação do projeto ou das especificações, para melhor adequação técnica aos seus objetivos;

b) quando necessária a modificação do valor contratual em decorrência de acréscimo ou diminuição quantitativa de seu objeto, nos limites permitidos por esta Lei. 
Percebe-se, portanto, que a própria Lei ao cuidar da validade da alteração, estipulou também suas condições. Assim, duas mudanças podem ser cabíveis, a qualitativa e a quantitativa, uma vez que estabelecem alterações no próprio projeto ou em suas especificações e acréscimo ou diminuição quantitativa do objeto, respectivamente (PIETRO, 2009, p. 268).

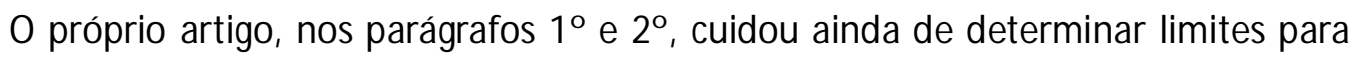
essas alterações. 0 §1ำ dispõe que até $25 \%$ de acréscimo ou supressão em obras, serviços ou compras e $50 \%$ em reformas de edifício ou de equipamentos serão mantidas nas mesmas condições do contrato inicial. Já o $§ 2^{\circ}$ estabelece que qualquer acréscimo ou supressão que exceda os valores acima serão vedados. Cumpre salientar que essas percentagens correspondem aos valores iniciais do contrato corrigidos para a data da alteração.

Deve-se observar, ainda, que este limite aplica-se tão somente à alteração a que faz alusão a alínea b do inciso I (M ELLO, 2005, p. 586).

Nesse mesmo sentido, de acordo com M aria Sylvia Zanella di Pietro:

Temos entendido que somente as alterações quantitativas estão sujeitas aos limites de $25 \%$ ou $50 \%$, referidos no artigo 65 , $\S 1$, da Lei $n 08.666$, até porque 0 inciso I, "b" (que trata especificamente dessa hipótese de alteração), faz expressa referência à modificação do valor contratual "em decorrência de acréscimo ou diminuição quantitativa de seu objeto, nos limites permitidos por esta lei", não se encontrando a mesma referência no inciso I, "a", que trata das alterações qualitativas (PIETRO, 2009, p.269).

Já a rescisão unilateral do contrato é aquela levada a cabo pela Administração Pública em razão de interesse público ou por inadimplemento de obrigações pelo contratado (SPITZCOVSKY, 2008, p. 343). Este tipo de rescisão também vem prevista na Lei 8.666/93, no art. 58, II, 78, incisos I a XII e XVII e 79, I.

No caso de rescisão por interesse público, deve sempre haver motivação do ato e garantia do contraditório e ampla defesa (MEDAUAR, 2009, p. 223). Ressalta-se ainda que nesta hipótese cabe ao contratado indenização pelos prejuízos comprovadamente sofridos, devolução de garantias, pagamentos devidos pela execução até a data da rescisão e pagamento do custo da desmobilização (art. 79, §2ํ).

Por outro lado, caso a rescisão se dê por inadimplemento do contratado, a este nada será devido, uma vez que foi ele quem deu causa à rescisão. Ao contrário, o 
inadimplente é quem sofrerá sanções, como assunção imediata do objeto do contrato, ocupação e utilização do local e o que mais fizer necessário para a execução do contrato, execução da garantia contratual para ressarcimento da Administração, e dos valores das multas e indenizações a ela devidos e, também, retenção dos creditos decorrentes do contrato até o limite dos prejuízos causados à Administração (art. 80 da Lei 8.666/93) (MELLO, 2005, p. 588).

\section{Equilíbrio econômico-financeiro}

Também conhecido como equação financeira, o equilíbrio econômico-financeiro do contrato corresponde à relação estabelecida entre os encargos do contratado e a remuneração oferecida pela Administração na formação inicial do contrato. Em virtude desta cláusula, uma vez determinado tal equilíbrio, ele não poderá mais ser desconsiderado, ou seja, ele "assegura ao particular contratado a manutenção daquela proporção durante a vigência do contrato" (M EDAUAR, 2009, p. 220).

Tem-se que, apesar da finalidade pública do contrato administrativo, 0 ente privado que 0 assina assim o faz visando a uma margem de lucro. Não cabe, porém, à Administração diluir ou minimizar esta margem, de modo que a proporção estabelecida no momento da celebração do contrato deva sempre ser mantida (MEDAUAR, 2009, p. 220).

Apontando para o mesmo entendimento, assim leciona Celso Antonio Bandeira de Mello:

Enquanto o particular procura o lucro, o Poder Público busca a satisfação de uma utilidade coletiva. Calha, pois, à Administração atuar em seus contratos com absoluta lisura e integral respeito aos interesses econômicos legítimos de seu contratante, pois não lhe assiste minimizá-los em ordem a colher benefícios econômicos suplementares ao previsto e hauridos em detrimento de outra parte (MELLO, 2005, p.602).

Conclui-se, então, que o equilíbrio econômico-financeiro foi estipulado para que 0 cumprimento do contrato se realize considerando aquilo que realmente foi compactuado, com todas as alterações posteriores, e não apenas levando em conta os valores brutos da data da celebração do mesmo. 


\section{Restrição ao uso da exceção do contrato não cumprido}

A exceção do contrato não cumprido, ou exceptio non adimpleti contractus, é um instituto do Direito Civil, consagrada no Código Civil arts. 476 e 477, estabelecendo que, em uma relação de contrato bilateral, um dos contratantes só poderá exigir o adimplemento do outro quando cumprida a sua obrigação (art. 476, CC). Assim, o descumprimento de ambas as partes contratantes resultaria na extinção tácita do contrato.

Sobre o tema, ainda no Direito Civil, com maestria ensina o professor Flávio Tartuce:

Por esse dispositivo, uma parte somente pode exigir que a outra cumpra com a sua obrigação, se primeiro cumprir com a própria (modalidade de exceptio doli, relacionada à boa-fé objetiva). Como efeito resolutivo, havendo descumprimento bilateral, ou seja, de ambas as partes, o contrato reputar-se-á extinto (TARTUCE, 2011, p. 560).

Tem-se, entretanto, que nos contratos administrativos, em virtude das prerrogativas da Administração, este direito não pode ser invocado pelo ente particular. Ou seja, por força do Princípio da Continuidade do Serviço Público e da Supremacia do Interesse Público, o particular não poderá suspender a execução do contrato alegando inadimplemento por parte da Administração (PIETRO, 2009, p. 275). 0 direito do ente particular restringe-se somente a requerer, administrativa ou judicialmente, 0 adimplemento ou a rescisão com indenização por perdas e danos.

Porém, como salientado acima, essa modalidade de rescisão é restrita, e não proibida nos contratos administrativos. A doutrina já vem conferindo exceções a esse posicionamento, considerando válida a inexecução do particular em algumas hipóteses. Tem-se que o interesse precípuo da continuidade cabe à Administração, portanto a ela será dirigido o dever de garantir todos os meios e condições necessários para que o particular execute 0 contrato. A partir do momento em que a falta da Administração caracterize inviabilidade para a execução por falta de condições materiais ou técnicas, o ente privado estará autorizado a exercer a exceção de contrato não cumprido (M EDAUAR, 2009, p. 221).

Além dessa posição doutrinária, a própria lei 8.666/93 tratou de especificar casos em que a rescisão contratual estaria motivada. Por força da lei, estará autorizado ao particular rescindir o contrato quando este estiver paralisado, por ordem da Administração, 
por prazo superior a 120 dias, salvo em casos de calamidade pública, grave perturbação da ordem interna ou guerra. A contagem dos 120 não necessita ser sequencial, ou seja, varias paralisações que, somadas, totalizem o mesmo montante de tempo autorizaria igualmente a rescisão. Autoriza-se, ainda, a rescisão, quando a Administração atrasar por mais de 90 dias os pagamentos relativos a obras, serviço ou fornecimento, excetuando-se, aqui, os mesmos casos já ditos acima. Por fim, caso a Administração não disponibilize área, local ou objeto para execução de obra, serviço ou fornecimento, desde que previstos no projeto, também estará ensejada a rescisão unilateral por parte do particular (art. 78, XIV, XV e XVI da Lei 8.666/93).

Conclui-se, portanto, que a exceptio non adimpleti contractus, sendo oriunda do Direito Civil, teve sua aplicação reduzida no que concerne aos contratos administrativos. Entretanto, como essa redução acaba, em sua grande maioria, sendo prejudicial ao ente privado, buscou-se estabelecer normas e situações para contornar tal injustiça, autorizando a aplicação da cláusula. A tendência no âmbito do mercado moderno e liberal é que, com o passar do tempo, a exceptio non adimpleti contractus seja aplicada integralmente aos contratos administrativos, tal e qual nos contratos regidos pelo Direito Civil.

\section{Fiscalização do contrato}

0 direito de fiscalizar o contrato celebrado é uma prerrogativa exclusiva da Administração Pública, não possuindo disposição semelhante nos contratos civis. Essa fiscalização vem tratada no art. 58, III, da Lei 8.666/93 e, embora o texto legal a denomine como uma prerrogativa, a fiscalização é na verdade um dever da Administração Pública (MEDAUAR, 2009, p. 221).

Para que se exerça tal fiscalização, a Administração deverá designar um representante especialmente para tal função, sendo permitida, ainda, a contratação de um terceiro a fim de auxiliá-lo e ainda subsidiá-lo de informações pertinentes a esta função (art. 67). Este fiscal designado deverá anotar em registro próprio todas as ocorrências presenciadas na execução dos contratos, determinando os procedimentos necessários à regularização das faltas ou defeitos. Deverá, ainda, no caso de decisões que ultrapassem sua competência, solicitá-las a seus superiores em tempo hábil para que os procedimentos necessários possam ser tomados e surtam o efeito desejado (art. 67, §§ $1^{\circ}$ e 2ํํ). 
Caso houver a solicitação de providências pelo representante e o particular não as cumprir, dará ensejo à rescisão unilateral do contrato, nos termos do art. 78, VII. Por fim, cumpre salientar ainda que a fiscalização não excluirá ou reduzirá a responsabilidade do contratado por danos causados à Administração ou a terceiros em virtude de dolo ou culpa (art. 70). Assim como, apesar da fiscalização, caberá ainda à Administração a possibilidade de aplicação de penalidades ao ente privado pela inexecução das obras, serviços ou fornecimentos.

\section{Aplicação de penalidades}

Mais uma vez se pautando pelo interesse público, a Administração poderá, além de fiscalizar a execução do contrato, aplicar sanções de natureza administrativa em casos de inexecução total ou parcial. Tal poder vem descrito no art. 87 da Lei 8.666/93 e seus incisos descrevem os tipos de penalidades aplicáveis:

\footnotetext{
I - advertência;

II - multa, na forma prevista no instrumento convocatório ou no contrato;

III - suspensão temporária de participação em licitação e impedimento de contratar com a Administração, por prazo não superior a 2 (dois) anos;

IV - declaração de inidoneidade para licitar ou contratar com a Administração Pública enquanto perdurarem os motivos determinantes da punição ou até que seja promovida a reabilitação perante a própria autoridade que aplicou a penalidade, que será concedida sempre que o contratado ressarcir a Administração pelos prejuízos resultantes e após decorrido o prazo da sanção aplicada com base no inciso anterior.
}

De acordo com $0 § 2^{\circ}$ do citado artigo, a pena de multa pode ser cumulada com qualquer uma das outras, enquanto que as demais devem ser aplicadas isoladamente entre si. A leitura ainda dos incisos acima destacado revela que o limite máximo da suspensão será de 2 anos. A declaração de idoneidade, por sua vez, não possui um limite fixado em lei, mas o emprego da expressão "após decorrido o prazo da sanção aplicada com base no inciso anterior" faz concluir que seu limite também será de 2 anos. Antes de discorrer sobre as penalidades de forma especifica, destaca-se ainda que ao contratado será garantido 0 direito de defesa, de acordo com o previsto no caput do art. 87 da Lei 8666/93 e no art. 5, LV da Constituição Federal (PIETRO, 2000, p. 272). 
A pena de advertência é a mais leve dentre as citadas, decorrentes de falhas de menor gravidade e deverá ser apresentada por escrito, apontando-se o fato que a gerou (MEDAUAR, 2009, p. 227).

Já a multa consiste num pagamento pecuniário por parte do entre privado, em decorrência de mora ou inexecução total ou parcial do contrato. A multa poderá ser cumulada com qualquer outra sanção. Pode, ainda, consistir na perda da garantia, se prestada; quando tal garantia for insuficiente, poder-se-á complementá-la com a dedução das importâncias devidas ao contratado (PIETRO, 2009, p. 273).

Já a suspensão temporária em licitar e o impedimento de contratar com a Administração, como dito acima, não podem exceder 2 anos e deverão ser aplicados por tempo proporcional à gravidade do fato (MEDAUAR, 2009, p. 222).

Por fim, a declaração de inidoneidade para licitar ou contratar com a Administração corresponde à sanção mais grave a ser aplicada ao ente particular. Somente após transcorridos 2 anos dessa declaração é que ele poderá solicitar sua reabilitação, mediante a própria autoridade coatora. Essa reabilitação, todavia, será concedida sempre que o contratado ressarcir a Administração Pública (M EDAUAR, 2009, p. 222).

A lei 8.666/93 ainda trata como crime, em seu art. 97 e parágrafo único, admitir a licitação com empresa ou profissional que tenha sido declarado inidôneo e, da mesma forma, comete crime aquele que, declarado inidôneo, celebra contrato com a Administração.

\section{Aplicação de sanções penais}

A lei 8.666/93 ainda apresenta um rol de situações agressivas ao interesse público praticadas em relação aos contratos administrativos que são qualificadas como crime (MELLO, 2005, p. 600). Esses ilícitos estão previstos nos arts. 89 a 99 da referida lei e apontam a atitudes como: dispensa de licitação sem previsão legal; fraudar licitação; impedir ou perturbar ato licitatório; quebrar sigilo de proposta licitatória; afastar ou mesmo tentar afastar licitante do processo; celebrar licitação com empresa ou profissional declarado inidôneo.

As penas aplicadas a estes ilícitos variam de acordo com a tipicidade e a gravidade destes, mas serão sempre de detenção, variando entre seis meses e seis anos, sem prejuízo 
da multa, nunca inferior a $2 \%$ nem superior a $5 \%$ do valor contratado. A lei prevê ainda que qualquer pessoa poderá buscar o Ministério Público, requerendo à instituição que proponha a ação penal. Em caso de omissão do Parquet e decurso do prazo legal sem a propositura da ação, poderá o requerente ajuizar ação penal privada subsidiária da pública (M ELLO, 2005, p. 600), onde o particular será o titular da ação e o MP deverá atuar na condição de "interveniente adesivo obrigatório", aditando a queixa, oferecendo denúncias alternativas ou substitutivas, acompanhando todos os atos processuais, interponto recursos, entre outras medidas (TOURINHO FILHO, 2010, p. 227-228).

\section{Conclusão}

Percebe-se, com a exposição proferida ao longo deste artigo, a enorme vantagem trazida pelas cláusulas exorbitantes à Administração Pública quando signatária de um contrato com um particular. Pautando-se quase sempre pelo Princípio da Supermacia do Interesse Público Sobre o Privado, a Administração ostenta uma condição que seria inadmissivel nos contratos entre particulares.

Tais privilégios, decorrentes da Lei 8.666 de 21 de junho de 1993, demonstram a intenção do legislador em tutelar, em primeiro lugar, os interesses públicos. Ou seja, dar-seá privilégio às realizações que tenham por objetivo 0 atendimento de toda a população. Somente a partir do momento em que o direito de todos coletivamente estejam tutelados é que o legislador permite que se atente para os direitos individuais. Em outras palavras, as realizações públicas sempre terão preferências sobre as privadas.

Hipóteses como alteração ou rescisão unilateral, fiscalização, aplicação de penalidades, entre outras, mostram essa preocupação. Espera-se, contudo, que o legislador continue apontando para o mesmo norte e que, apesar do mundo cada vez mais individualista atualmente, os interesses públicos voltados para o bem comum da população possa sempre prevalecer sobre os privados.

\section{Referências bibliográficas}

AGUILAR, Ana Patrícia. Contratos de Gestão. Jus Navigandi, Teresina, n. 491, ano 4. Disponível em http://jus.uol.com.br/revista/texto/5913. Acesso em: 7 de abril de 2011. 
BRASIL. Lei no 8.666 de 21 de junho de 1993. Regulamenta o art. 37, inciso XXI da Constituição Federal, institui normas para licitações e contratos da Administração Pública e dá outras providências. Disponível em «ttp://www.planalto.gov.br/ccivil_03/leis/L8666compilado.htm>. Acesso em: 4 de abril de 2011.

BRASIL. Lei № 8.987 de 13 de fevereiro de 1995. Dispõe sobre o regime de concessão e permissão da prestação de serviços públicos previsto no art. 175 da Constituição Federal, e dá outras providências. Disponível em < http://www.planalto.gov.br/ccivil_03/leis/_L8987compilada.htm>. Acesso em: 4 de abril de 2011.

BRAZ, Petrônio. Tratado de Direito M unicipal, v. 2. 3ạ ed. Leme/SP: M undo Jurídico, 2009.

M EDAUAR, Odete. Direito Administrativo M oderno. 13ạ ed. São Paulo: Revista dos Tribunais, 2009.

M ONTEIRO, Washington de Barros. Curso de Direito Civil, v. 1: Parte Geral. 39ạ ed. São Paulo: Saraiva, 2003.

M ELLO, Celso Antonio Bandeira de. Curso de Direito Administrativo. 18ạ ed. São Paulo:

M alheiros Editores, 2005.

PIETRO, M aria Sylvia Zanella di. Direito Administrativo. 22ª ed. São Paulo: Atlas, 2009.

SPITZCOVSKY, Celso. Direito Administrativo. 10ạ ed. São Paulo: M étodo, 2008.

TARTUCE, Flávio. Manual de Direito Civil volume único. 1ª ed. São Paulo: Método, 2011.

TOURINHO FILHO, Fernando Costa. Manual de Processo Penal. 13a ed. São Paulo: Saraiva, 2010.

VENOSA, Silvio de Salvo. Direito Civil v. 2. 4a ed. São Paulo: Atlas, 2004.

Artigo recebido em:

10 abr. 2011

Artigo aprovado em:

10 nov. 2011 